\title{
Vitamin B intake and status in healthy Havanan men, 2 years after the Cuban neuropathy epidemic
}

\author{
Josiane Arnaud $^{1 *}$, Pedro Fleites-Mestre ${ }^{2}$, Michelle Chassagne ${ }^{3}$, Tomas Verdura ${ }^{4}$, Isabel Garcia Garcia ${ }^{5}$, \\ Teresa Hernandez-Fernandez ${ }^{2}$, Hortensia Gautier ${ }^{6}$, Alain Favier ${ }^{1}$, Rafael Pérez-Cristià ${ }^{2}$, \\ Jacques Barnouin $^{3}$ and Neuropathy epidemic group ${ }^{7}$ \\ ${ }^{1}$ Département de Biologie Intégrée, CHUG, BP 217, 38043 Grenoble Cedex 9, France \\ ${ }^{2}$ Centro National de Toxicologia (CENATOX), Ave 31 y calle 114, La Habana, Cuba \\ ${ }^{3}$ INRA, Unité d'Ecopathologie, CRZV de Theix, 63122 Saint Genès Champanelle, France \\ ${ }^{4}$ Instituto Finlay, Ave 27, no 19805, La Lisa, Ciudad de la Habana, Cuba \\ ${ }^{5}$ Instituto de Farmacia y Alimentos, La Coronela, La Lisa, Ciudad de la Habana, Cuba \\ ${ }^{6}$ Instituto de Hematologia e Immunologia, San Francisco y Perla, Alta Habana, Boyeros, cod.10800 La Habana, Cuba \\ ${ }^{7}$ Neuropathy epidemic group: C Campa Huergo and G Sierra Gonzales from Instituto Finlay, Ciudad de la Habana, Cuba; \\ T Conill Diaz, \\ E Alvarez Pérez from Centro Nacional de Toxicologia (CENATOX), La Habana, Cuba; A Galan and \\ L Ledesma from Instituto de Farmacia y Alimentos (IFAL), Ciudad de la Habana, Cuba; I Mesa Martin and \\ L Regal Izquierdo from Sectorial de Salud La Lisa, Ciudad de la Habana, Cuba; C Serrano Verdura from \\ Direccion Nacional de Epidemiologica, MINSAP, La Habana, Cuba
}

(Received 8 June 2000 - Revised 20 November 2000 - Accepted 5 January 2001)

\begin{abstract}
A prospective epidemiological study was carried out over 1 year to evaluate vitamin B complex dietary intake and status in Cuba, 2 years after the Cuban neuropathy epidemic of 1993. Of the 199 healthy middle-aged men selected, 141 completed the study. Volunteers were followed up every 3 months for 1 year. Dietary intake and status of thiamin, riboflavin, vitamin $\mathrm{B}_{6}$, folate and vitamin $B_{12}$ were assessed each time. The dietary intake of vitamin $B$ complex was low, particularly in June and July (folate), and October (thiamin). A deficient status was observed for vitamin $\mathrm{B}$ complex, except for vitamin $\mathrm{B}_{6}$. Vitamin $\mathrm{B}$ complex intake and status varied over the year. However, dietary intake and status were poorly related. The results prove that healthy Cuban men represent a vulnerable population in terms of vitamin B complex status and stress the necessity to both promote preventive multivitamin supplementation and produce local food rich in vitamin $\mathrm{B}$ complex.
\end{abstract}

Vitamin B complex: Seasonal variation in intake: Blood indices

From 1991 to 1993,50862 cases $(461 \cdot 4 / 100000$ inhabitants) of optic and peripheral neuropathies were reported in Cuba (Tucker \& Hedges, 1993; Pérez-Cristià \& Fleites-Mestre, 1994; Roman, 1994; Bowman et al. 1996; Macias-Matos et al. 1996). Food shortage, depletion in micronutrients (particularly in vitamin B complex) and smoking habits were major risk factors of the Cuban neuropathy epidemic (Bowman et al. 1996; Macias-Matos et al. 1996). In tropical countries similar optic and peripheral neuropathies have been attributed to thiamin, folate or vitamin $\mathrm{B}_{12}$ deficiencies (Roman, 1994; Bowman et al. 1996; Sainte-Foie et al. 1997; Dolin et al. 1998). However, during the Cuban neuropathy epidemic, the severity of vitamin B complex deficiencies was similar in both patients with neuropathy and control subjects (Tucker \& Hedges, 1993; Macias-Matos et al. 1996). Nevertheless, the number of new cases decreased and most patients suffering from neuropathy $(99.9 \%)$ improved significantly after the May 1993 nationwide distribution of multivitamin supplement (containing (mg): thiamin $2 \cdot 5$, riboflavin $1 \cdot 6$,

Abbreviations: EAST-AC, erythrocyte aspartate aminotransferase activation coefficient; EGR-AC, erythrocyte glutathione reductase activation coefficient; ETK-AC, erythrocyte transketolase activation coefficient; SECUBA, multidisciplinary epidemiological research programme.

* Corresponding author: Dr Josiane Arnaud, fax +33 4767658 21, email Josiane.Arnaud@ujf-grenoble.fr 
niacin 20, folate $230 \mu \mathrm{g}$, vitamin $\mathrm{B}_{6} 2$, vitamin $\mathrm{B}_{12} 6 \mu \mathrm{g}$, vitamin A as retinol 0.75) (Tucker \& Hedges, 1993; Macias-Matos et al. 1996). This nationwide multivitamin supplementation was continued for 1 year.

The present study was part of a prospective multidisciplinary epidemiological research programme (SECUBA; Barnouin \& Pérez-Cristià, 1998) and was carried out 2 years after the peak of the Cuban neuropathy epidemic in 1993. At that time, the Cuban population did not take multivitamin supplements and the economic situation in Cuba was particularly worrying, but only a few new neuropathy cases had been reported. The major objective of SECUBA was to improve the long-term safety of food in Cuba and to follow the potential risk factors highlighted during the Cuban neuropathy epidemic.

The present study focused on the evaluation of thiamin, riboflavin, vitamin $\mathrm{B}_{6}$, folate and vitamin $\mathrm{B}_{12}$ dietary intake and biological status, and their changes over a 12-month period (from March 1995 to February 1996) in healthy Havanan men. Even though no clear relationship between vitamin B complex deficiencies and neuropathy was demonstrated during the Cuban neuropathy epidemic, the prevalence of vitamin B complex deficiency in the Cuban population could reflect a major health risk.

\section{Methods \\ Volunteers}

A random selection of 199 healthy urban representative middle-aged male volunteers was made from La Lisa (Havana) health centres. The mean age was 39 years (range 27-59 years), with 102 current smokers, thirty-two former smokers and sixty-five non-smokers. The age and gender of the volunteers corresponded to that of the population most affected by the optic form of the Cuban neuropathy epidemic (Tucker \& Hedges, 1993; Roman, 1994). Havana was selected for practical reasons, but also because the incidence of the Cuban neuropathy epidemic in Havana corresponded to the average for Cuba as a whole. Information regarding social and demographic characteristics, education, occupation and exposure to asbestos, heavy metals, radiation, pesticides and other chemicals was obtained by interview. Of the volunteers, $16 \%$ occasionally took low doses of multivitamin supplement (one to seventeen pills per week) from 3 months before inclusion to the end of the study. Values for these individuals were included in the analysis as their exclusion did not materially affect the results.

\section{Study design}

Volunteers were followed up four times at 3-month intervals (i.e. period 1 March-April 1995, period 2 JuneJuly 1995, period 3 October 1995, period 4 JanuaryFebruary 1996). April corresponds to the end of the dry season. October corresponds to the transition between rainy and dry seasons. Complete medical examination, BMI calculation, blood collection and assessment of dietary intake were performed at each follow-up.

Of the 199 volunteers, 141 underwent the complete biological study. However, because of insufficient available blood samples, complete biological data for vitamin B complex status were obtained in only 127 volunteers. The dietary and life-habit questionnaires were completed every time by 106 volunteers. The reasons for drop-out were illness, moving or a different job site at the time of clinical, nutritional and biological assessment. However, those volunteers who completed the study and those who did not were similar in termes of age, BMI, race, smoking habits, vitamin supplement use, years of education and employment (Arnaud et al. 2001).

The study protocol was approved by the Cuban Ministry of Public Health, and all volunteers gave their informed written consent. Procedures followed were in accordance with Anon (1994).

\section{Assessment of dietary intake}

Food and beverage consumption was quantified by volunteers (household ware) in all periods for seven consecutive days. At the end of each day, a trained dietitian checked by interview information on the food and beverage record for composition and quantity accuracy, completeness and clarity. Nutrient intake was calculated using the Cuban NUTRISIS food composition database (Rodriguez et al. 1992) which contains the nutrient contents of the most commonly consumed food and beverages ( $n$ 628) in Cuba. Nutritional density was calculated as $\mathrm{mg} / \mathrm{gl}$ vitamin/5 MJ.

\section{Blood collection, storage and transport}

Blood was collected by venepuncture after overnight fasting in a heparinised vacuum tube and a vacuum tube containing no additive (Becton Dickinson, Pont de Claix, France). The tubes were protected from light and stored on ice immediately after collection. The blood samples were delivered to the Cuban laboratory within $30 \mathrm{~min}$ of venepuncture. The tubes were centrifuged at $1700 \mathrm{~g}$ for $10 \mathrm{~min}$ at $4{ }^{\circ} \mathrm{C}$ to separate serum or plasma. The buffy coat was then removed from the heparin-treated tube and the remaining erythrocytes were subjected to vortexing in order to obtain a homogeneous cellular suspension before cell sampling. Aliquots of serum (for folate and vitamin $B_{12}$ determinations) and erythrocytes (for erythrocytes transketolase activation coefficient (ETK-AC), erythrocytes glutathione reductase activation coefficient (EGR-AC) and erythrocyte aspartate aminotransferase activation coefficient (EAST-AC) determinations) were frozen and stored at $-20^{\circ} \mathrm{C}$ within $2 \mathrm{~h}$ of sampling. Samples were kept frozen until analysed and thawed only once before assay. Determinations were performed within 1 month.

\section{Blood analysis}

Thiamin, riboflavin and pyridoxal phosphate status were evaluated respectively by ETK-AC EGR-AC and EASTAC according to previously published methods (Nichoalds et al. 1974; Bayoumi \& Rosalki, 1976) at the Département de Biologie Intégrée. Enzyme activity was determined with and without added coenzymes (thiamin pyrophosphate, FAD and pyridoxal-5-phosphate respectively). The activity 
Table 1. Daily dietary intake vitamin B complex in healthy Havanan male volunteers $(n$ 106) evaluated at 3-month-intervals over 1 year $\dagger$ (Mean values and standard deviations)

\begin{tabular}{|c|c|c|c|c|c|c|c|c|c|c|c|c|c|}
\hline \multirow[b]{2}{*}{ Period $^{*}$} & \multicolumn{2}{|c|}{1} & \multirow[b]{2}{*}{$P \ddagger$} & \multicolumn{2}{|c|}{2} & \multirow[b]{2}{*}{$P \ddagger$} & \multicolumn{2}{|c|}{3} & \multirow[b]{2}{*}{$P \ddagger$} & \multicolumn{2}{|c|}{4} & \multirow[b]{2}{*}{$P \S$} & \multirow[b]{2}{*}{ RDA } \\
\hline & Mean & SD & & Mean & SD & & Mean & SD & & Mean & SD & & \\
\hline Thiamin (mg/d) & 0.87 & 0.25 & 0.019 & $0 \cdot 81$ & 0.24 & 0.022 & 0.74 & 0.23 & 0.027 & 0.81 & 0.24 & 0.001 & 1.5 \\
\hline Riboflavin (mg/d) & 0.79 & 0.25 & & 0.85 & 0.36 & & 0.84 & 0.40 & & 0.86 & 0.36 & 0.761 & 1.7 \\
\hline Vitamin $B_{6},(\mathrm{mg} / \mathrm{d})$ & $1 \cdot 26$ & 0.37 & 0.020 & $1 \cdot 20$ & 0.32 & & $1 \cdot 13$ & 0.30 & & 1.09 & 0.32 & 0.001 & $2 \cdot 0$ \\
\hline Folate $(\mu \mathrm{g} / \mathrm{d})$ & 152 & 49 & 0.007 & 137 & 39 & & 146 & 43 & 0.0001 & 172 & 57 & 0.001 & 200 \\
\hline
\end{tabular}

RDA, recommended dietary allowances (National Research Council, 1989).

* Period 1, March and April 1995; period 2, June and July 1995; period 3, October 1995; period 4, January and February 1996; periods 2 and 3, rainy season.

† For details of subjects and procedures, see p. 742.

$\ddagger$ Significance of probability of a difference between periods.

$\S$ Significance of probability of period effect.

ratio (with:without coenzymes) provided the erythrocyte activation coefficients. The variability of measures was controlled by using pools of erythrocytes stored at $-20^{\circ} \mathrm{C}$ in small aliquots. The performance of a new pool of erythrocytes was compared with that of the previous pool. These samples were stable for at least 5 weeks for ETKAC, 7 weeks for EGR-AC and 4 weeks for EAST-AC. The between-day CV was $3.0 \%$ for ETK-AC, $4.8 \%$ for EGR$\mathrm{AC}$ and $4.0 \%$ for EAST-AC. The values obtained in a French blood-donor population $(n$ 80) were $1 \cdot 16$ (SD 0.11) for ETK-AC, 1.17 (SD 0.12) for EGR-AC and 1.68 (SD $0 \cdot 16$ ) for EAST-AC. Serum folate and vitamin $B_{12}$ were determined simultaneously using a competitive proteinbinding assay (Quantaphase II; Eria Diagnostic, Marnes la Coquette, France) at the Instituto de Hematologie e Immunologia. Low and normal range serum internal quality controls (Bio Rad, Iory sur Seine, France) were used to ensure the accuracy and precision of measures. With this method, values obtained in well-nourished Cubans were in the range of reference values indicated by the manufacturer.

\section{Statistics}

Statistical analysis was performed using SAS software (SAS Institute, Cary, NC, USA). Individual measures of vitamin intake and status and of food consumption were normalised by logarithmic or square root transformation when necessary. For each variable, means, medians, and standard deviations were calculated for the four periods using data from all the volunteers with a complete set of measures. Response trends over time were assessed by variance-covariance analyses on repeated measures using the mixed-model SAS methodology (Littell et al. 1998).
This procedure computes efficient estimates of fixed (time period and smoking habits) and random (individual) effects when a covariance structure, referring to variance at individual times (variation between volunteers) and a correlation between measures at different times on the same subject (covariation within volunteers), characterises the data. McNemar's test was performed to evaluate the changes in the frequency of vitamin deficiencies according to periods. McNemar's test assesses the significance of the difference between two dependent samples when the variable of interest is dichotomous. It uses chi-square distribution applied to pair samples (Lei et al. 1998). Spearman correlations were performed between the standardised values of absolute intake or nutrient densities and the standardised values of biological status for individual components of the vitamin B complex. Adjusted Spearman correlations were also performed (Tomassone et al. 1993). Factors known to influence micronutrient status (i.e. age, years of education, BMI, number of cigarettes smoked per $\mathrm{d}$, number of vitamin tablets per week, energy and alcohol intake) were selected as adjustment variables. All tests were considered significant at $P<0.05$.

\section{Results}

Vitamin B complex intake by period is indicated in Table 1 . The percentage of volunteers with values below two-thirds of the recommended dietary allowances (National Research Council, 1989) is indicated in Table 2. Significant period effects were observed for thiamin, vitamin $\mathrm{B}_{6}$ and folate daily dietary intake $(P=0.001$ in all cases). Thiamin daily dietary intake decreased regularly from March 1995 to October 1995 and increased between October 1995 and February 1996. Vitamin $\mathrm{B}_{6}$ daily dietary intake decreased

Table 2. Percentage of healthy Havanan male volunteers $(n$ 106) with daily dietary intake under two-thirds the US recommended dietary allowances (National Research Council, 1989) calculated at 3-month intervals over 1 year†

\begin{tabular}{lccccccc}
\hline & Period $1^{*}$ & $P \ddagger$ & Period $2^{*}$ & $P \ddagger$ & Period 3* $^{*}$ & $P \ddagger$ & $P^{*}$ \\
\hline Thiamin $<1.0 \mathrm{mg} / \mathrm{d}$ & 74.5 & 0.369 & 79.2 & 0.095 & 87.7 & 0.041 \\
Riboflavin $<1.13 \mathrm{mg} / \mathrm{d}$ & 91.5 & 0.050 & 83.0 & 0.275 & 87.7 & 78.3 \\
Vitamin $\mathrm{B}_{6}<1.33 \mathrm{mg} / \mathrm{d}$ & 61.3 & 0.114 & 70.8 & 0.353 & 75.5 & 0.1314 \\
Folate $<133 \mu \mathrm{g} / \mathrm{d}$ & 34.9 & 0.093 & 45.3 & 0.773 & 47.2 & 0.001 & 83.0 \\
\hline
\end{tabular}

* Period 1, March and April 1995; period 2, June and July 1995; period 3, October 1995; period 4, January and February 1996; periods 2 and 3 rainy season.

$\dagger$ For details of subjects and procedures, see p.742.

$\ddagger$ Significance of probability of a difference between periods (McNemar's test). 
Table 3. Daily intakes of various food and food groups, energy, proteins and carbohydrates in healthy Havanan male volunteers ( $n$ 106) evaluated at 3-month intervals over 1 yearł

(Mean values and standard deviations)

\begin{tabular}{|c|c|c|c|c|c|c|c|c|c|c|c|c|}
\hline \multirow[b]{2}{*}{ Period§ ... } & \multicolumn{2}{|c|}{1} & \multirow[b]{2}{*}{$P \emptyset$} & \multicolumn{2}{|c|}{2} & \multirow[b]{2}{*}{$P ף$} & \multicolumn{2}{|c|}{3} & \multirow[b]{2}{*}{$P \emptyset$} & \multicolumn{2}{|c|}{4} & \multirow[b]{2}{*}{ P\# } \\
\hline & Mean & SD & & Mean & SD & & Mean & SD & & Mean & SD & \\
\hline Bread, cereals, beans and tubers: $\mathrm{g} / \mathrm{d}$ & $\begin{array}{l}719 \\
35 \cdot 7^{*}\end{array}$ & 21 & 0.005 & $\begin{array}{c}644 \\
35.5\end{array}$ & 18 & & $\begin{array}{l}621 \\
36.7\end{array}$ & $\begin{array}{c}16 \\
1 \cdot 3\end{array}$ & & $\begin{array}{r}588 \\
35.9\end{array}$ & $\begin{array}{c}18 \\
1.4\end{array}$ & 0.0001 \\
\hline Vegetables, fruit and fruit juice, $(\mathrm{g} / \mathrm{d})$ & 153 & 12 & 0.001 & 92 & 7 & & 89 & 5 & 0.0001 & 202 & 12 & 0.0001 \\
\hline Milk and dairy products $(\mathrm{g} / \mathrm{d})$ & 91 & 8 & & 123 & 11 & & 111 & 10 & & 108 & 12 & 0.0670 \\
\hline Meat $(g / d)$ & $51 \dagger$ & 3 & & 57 & 4 & & 58 & 4 & & 67 & 4 & 0.0235 \\
\hline Eggs (g/d) & 34 & 2 & 0.001 & 19 & 2 & 0.007 & 27 & 2 & & 27 & 2 & 0.0010 \\
\hline Fish, shellfish and crustacea $(\mathrm{g} / \mathrm{d})$ & 31 & 2 & 0.0075 & 42 & 3 & & 36 & 2 & & 35 & 3 & 0.0132 \\
\hline Alcoholic beverages $(\mathrm{g} / \mathrm{d})$ & 47 & 11 & & 59 & 10 & & 58 & 12 & & 59 & 9 & 0.4890 \\
\hline Other type of food\| $(\mathrm{g} / \mathrm{d})$ & 215 & 17 & & 182 & 13 & 0.036 & 143 & 12 & & 152 & 14 & 0.0040 \\
\hline Energy $(\mathrm{MJ} / \mathrm{d})$ & 7.0 & $2 \cdot 0$ & & 6.9 & 1.9 & & 6.7 & 1.8 & & 6.6 & 1.8 & $0 \cdot 1050$ \\
\hline Proteins $(\mathrm{g} / \mathrm{d})$ & 61 & 16 & & 64 & 16 & & 62 & 16 & & 62 & 16 & 0.7320 \\
\hline Carbohydrates, $(\mathrm{g} / \mathrm{d})$ & 258 & 74 & 0.007 & 236 & 66 & & 237 & 67 & & 235 & 70 & 0.0100 \\
\hline
\end{tabular}

Mean value $(\mathrm{g} / \mathrm{d})$ was significantly higher in period 1 than in period $4:{ }^{*} P=0.004$

Mean value was significantly lower in period 1 than in period $4: \dagger P=0.020$

$\ddagger$ For details of subjects and procedures, see p. 742.

$\S$ Period 1, March and April 1995; period 2, June and July 1995; period 3, October 1995; period 4, January and February 1996; Periods 2 and 3, rainy season.

\| Other types of food include sugar and sweets, oils and fat products, non-alcoholic beverages (except for fruit juice), soup and combined dishes.

I Significance of probability of a difference between periods.

\# Significance of probability of period effect.

between March 1995 and July 1995 and remained similar from July 1995 to February 1996. Folate daily dietary intake was lower during the rainy season (periods 2 and 3 ) than during the dry season (periods 1 and 4). As indicated in Table 2, more than $60 \%$ of the volunteers had daily dietary intakes below two-thirds of the recommended dietary allowances (National Research Council, 1989) for thiamin, riboflavin and vitamin $\mathrm{B}_{6}$ for all the periods studied. For folate dietary intake, these percentages varied from 24.5 to 47.2 , depending on the periods.

Table 3 shows the mean daily consumption of energy, macronutrients and various food or food groups known to have an effect on vitamin B complex intake and biological status. Vegetable and fruit intake was significantly lower in the rainy season (periods 2 and 3 ) than in the dry season (periods 1 and 4; $P=0 \cdot 0001$ ). Between March 1995 and July 1995, intakes of bread, cereals, beans and tubers decreased along with carbohydrate intake, whereas seafood consumption increased. Finally, egg consumption was lowest in June and July 1995.
Vitamin status is indicated in Table 4 and the percentage of volunteers assessed under the cut-off values of vitamin deficiencies proposed by a European group of experts (Van den Berg et al.1993) is indicated in Table 5. Statistically significant differences between periods were observed for vitamin status. An improvement in both thiamin and pyridoxal status occurred between March 1995 and July 1995. A significant decline in riboflavin status was observed in January and February 1996, compared with the three other periods $(P=0 \cdot 040)$. Serum folate concentrations indicated that folate status was lowest in June and July 1995 and highest in October 1995. Serum vitamin $B_{12}$ concentrations and the percentage of values under $100 \mathrm{pmol} / \mathrm{l}$ indicated an improvement in vitamin $\mathrm{B}_{12}$ status in periods 3 and 4 compared with periods 1 and 2. Serum folate and vitamin $\mathrm{B}_{12}$ concentrations were extremely low. As indicated in Table 5, >20\% of volunteers were deficient in thiamin and riboflavin, and more than $60 \%$ of volunteers were folate deficient. The percentage of volunteers suffering from vitamin $\mathrm{B}_{12}$ deficiency varied

Table 4. Blood vitamin B status indices in healthy Havanan male volunteers measured at 3-month intervals over 1 year* (Mean values and standard deviations)

\begin{tabular}{|c|c|c|c|c|c|c|c|c|c|c|c|c|c|}
\hline \multirow[b]{2}{*}{ Period† ... } & \multirow[b]{2}{*}{$n$} & \multicolumn{2}{|c|}{1} & \multirow[b]{2}{*}{$P \ddagger$} & \multicolumn{2}{|c|}{2} & \multirow[b]{2}{*}{$P \ddagger$} & \multicolumn{2}{|c|}{3} & \multirow[b]{2}{*}{$P \ddagger$} & \multicolumn{2}{|c|}{4} & \multirow[b]{2}{*}{$P \S$} \\
\hline & & Mean & SD & & Mean & SD & & Mean & SD & & Mean & SD & \\
\hline ETK-AC & 127 & $1 \cdot 23$ & $0 \cdot 14$ & 0.020 & $1 \cdot 19$ & 0.13 & & $1 \cdot 21$ & $0 \cdot 12$ & & $1 \cdot 24$ & $0 \cdot 17$ & 0.010 \\
\hline EGR-AC & 134 & 1.57 & 0.32 & & 1.59 & 0.35 & & 1.54 & 0.34 & 0.004 & 1.61 & 0.33 & 0.040 \\
\hline EAST-AC & 134 & 1.77 & 0.28 & 0.001 & 1.61 & 0.24 & & 1.69 & 0.32 & & 1.64 & 0.34 & 0.001 \\
\hline Serum folate $(\mathrm{nmol} / \mathrm{l})$ & 128 & 4.7 & $2 \cdot 7$ & 0.006 & $4 \cdot 1$ & $2 \cdot 4$ & 0.001 & $6 \cdot 7$ & 4.4 & 0.001 & $4 \cdot 7$ & $2 \cdot 7$ & 0.001 \\
\hline Serum vitamin $\mathrm{B}_{12}(\mathrm{pmol} / \mathrm{l})$ & 133 & 100 & 55 & & 106 & 53 & 0.001 & 156 & 72 & 0.030 & 145 & 68 & 0.001 \\
\hline
\end{tabular}

EAST-AC, erythrocyte aspartate aminotransferase activation coefficient used as an index of vitamin $B_{6}$ status. EGR-AC, erythrocyte glutathione reductase activation coefficient used as an index of riboflavin status, ETK-AC, erythrocyte transketolase activation coefficient used as an index of thiamin status.

* For details of subjects and procedures, see p. 742.

† Period 1, March and April 1995; period 2, June and July 1995; period 3, October 1995; period 4, January and February 1996; periods 2 and 3, rainy season. ¥ Signifiance of probability of a difference between periods.

$\S$ Significance of probability of period effect. 
Table 5. Percentage of vitamin B complex-deficient healthy Havanan male volunteers using the deficiency cut-offs proposed by a European group of experts (Van den Berg et al.1993), evaluated at 3-month intervals over 1 year*

\begin{tabular}{|c|c|c|c|c|c|c|c|c|}
\hline & $n$ & Period 1† & $P \ddagger$ & Period 2† & $P \ddagger$ & Period 3† & $P \ddagger$ & Period $4 \dagger$ \\
\hline ETK-AC $>1.25$ & 127 & 39.4 & 0.003 & $22 \cdot 0$ & 0.022 & $33 \cdot 9$ & 0.446 & $38 \cdot 6$ \\
\hline EGR-AC $>1.7$ & 134 & $30 \cdot 6$ & 0.435 & $34 \cdot 3$ & 0.209 & $29 \cdot 1$ & 0.016 & $39 \cdot 6$ \\
\hline EAST-AC $>2.4$ & 134 & $2 \cdot 2$ & 0.317 & 0.7 & 0.317 & $2 \cdot 2$ & 0.317 & 0.7 \\
\hline Serum folate $<7 \mathrm{nmol} / \mathrm{l}$ & 128 & $85 \cdot 2$ & 0.251 & $89 \cdot 1$ & 0.001 & $64 \cdot 1$ & 0.001 & $82 \cdot 0$ \\
\hline Serum vitamin $B_{12}<100 \mathrm{pmol} / \mathrm{l}$ & 133 & $53 \cdot 4$ & 0.876 & $52 \cdot 6$ & 0.001 & $18 \cdot 0$ & 0.170 & $24 \cdot 1$ \\
\hline
\end{tabular}

EAST-AC, erythrocyte aspartate aminotransferase activation coefficient used as an index of vitamin $\mathrm{B}_{6}$ status; EGR-AC, erythrocyte glutathione reductase activation coefficient used as an index of riboflavin status; ETK-AC, erythrocyte transketolase activation coefficient used as an index of thiamin status.

* For details of subjects and procedures, see p. 742

† Period 1, March and April 1995; period 2, June and July 1995; period 3, October 1995; period 4, January and February 1996; periods 2 and 3, rainy season.

$\ddagger$ Significance of probability of a difference between periods (McNemar's test)

between $20 \%$ (periods 3 and 4) and $50 \%$ (periods 1 and 2). Despite low vitamin $B_{6}$ intake, the corresponding status remained adequate.

Spearman correlation coefficients are reported in Table 6. No significant correlation was observed between thiamin intake and status. Correlation between riboflavin, vitamin $\mathrm{B}_{6}$ or folate intake and the corresponding biological status depended on periods, intake expression (absolute intake or nutritional densities) and adjustment. No significant correlation was observed between absolute dietary intake and biological status, except for riboflavin in JanuaryFebruary $1996(r-0 \cdot 194, n 129, P=0.027)$ and for folate in March-April $1995(r-0 \cdot 187, n 181, P=0.012)$. The three models presented a significant relationship between riboflavin intake and status in January and February 1996.

\section{Discussion}

In Havanan men, vitamin B complex dietary intake was low compared with reported values for adult men in developed countries (Costa de Carvalho et al. 1996; Brants et al. 1997; Alberti-Fidanza et al. 1998; Bell et al. 1998). As far as we know, few studies have been conducted in developing countries, particularly in adult males. Compared with the dietary intakes observed in Cuba at the beginning of the neuropathy epidemic in 1992, the energy and folate daily dietary intakes reported in the present study were lower (Pérez-Cristià \& Fleites-Mestre, 1994). In contrast, thiamin and protein daily dietary intakes were higher than those in 1992 (Pérez-Cristià \& Fleites-Mestre, 1994). In addition, vitamin $B_{6}$ and riboflavin dietary intakes were similar to those reported in 1992 (PérezCristià \& Fleites-Mestre, 1994). The low energy intake probably makes it difficult to meet vitamin B complex requirements, and therefore contributes to the fact that a high percentage of Cuban volunteers present with thiamin, riboflavin and vitamin $\mathrm{B}_{6}$ daily dietary intakes below twothirds of the recommended dietary allowances (National Research Council, 1989). The low vitamin intake in the Cuban population studied suggests that this population is at risk for vitamin B complex deficiencies and thus for neuropathy, although when the present study was done few cases of neuropathy had been reported. This low incidence of neuropathy contrasts with the very severe economic crisis, the low dietary intake of vitamin B complex and the low consumption of multivitamin supplements. Nevertheless, when a risk factor is very common in a population, its prevalence may reflect a risk even if its presence in an individual is not predictive of disease (Bowman et al. 1996).

Table 6. Spearman correlation coefficients for correlation between standardised vitamin B complex daily dietary intake and status for healthy Havanan male volunteers

\begin{tabular}{|c|c|c|c|c|c|c|c|c|c|}
\hline \multirow{2}{*}{$\begin{array}{l}\text { Period }^{*} \ldots \\
\text { Correlation } \\
\text { model }\end{array}$} & & \multicolumn{2}{|c|}{1} & \multicolumn{2}{|c|}{2} & \multicolumn{2}{|c|}{3} & \multicolumn{2}{|c|}{4} \\
\hline & & $\begin{array}{c}\text { Nutritional } \\
\text { density }\end{array}$ & $\begin{array}{c}\text { Adjusted } \\
\text { model } \ddagger\end{array}$ & $\begin{array}{c}\text { Nutritional } \\
\text { density } \dagger\end{array}$ & $\begin{array}{c}\text { Adjusted } \\
\text { model } \ddagger\end{array}$ & $\begin{array}{c}\text { Nutritional } \\
\text { density } \dagger\end{array}$ & $\begin{array}{c}\text { Adjusted } \\
\text { model } \neq\end{array}$ & $\begin{array}{c}\text { Nutritional } \\
\text { density } \dagger\end{array}$ & $\begin{array}{c}\text { Adjusted } \\
\text { model }\end{array}$ \\
\hline \multirow[t]{3}{*}{ Thiamin } & $r$ & 0.050 & -0.026 & -0.094 & -0.117 & 0.028 & 0.066 & 0.087 & 0.078 \\
\hline & $P$ & 0.497 & 0.727 & 0.292 & 0.191 & 0.736 & 0.445 & 0.338 & 0.406 \\
\hline & $n$ & 188 & 188 & 138 & 135 & 148 & 142 & 123 & 123 \\
\hline \multirow[t]{3}{*}{ Riboflavin } & $r$ & -0.102 & -0.061 & -0.143 & -0.094 & -0.145 & -0.149 & -0.261 & -0.229 \\
\hline & $P$ & 0.164 & 0.414 & 0.092 & 0.287 & 0.077 & 0.083 & 0.003 & 0.011 \\
\hline & $n$ & 187 & 187 & 140 & 137 & 149 & 149 & 129 & 129 \\
\hline \multirow[t]{3}{*}{ Vitamin $B_{6}$} & $r$ & -0.148 & 0.097 & -0.181 & -0.207 & 0.050 & 0.041 & 0.004 & -0.029 \\
\hline & $P$ & 0.043 & 0.194 & 0.031 & 0.018 & 0.545 & 0.637 & 0.961 & 0.755 \\
\hline & $n$ & 188 & 188 & 141 & 138 & 148 & 142 & 129 & 129 \\
\hline \multirow[t]{3}{*}{ Folate } & $r$ & 0.164 & 0.138 & 0.057 & 0.103 & 0.297 & 0.235 & 0.175 & 0.185 \\
\hline & $P$ & 0.027 & 0.071 & 0.510 & 0.249 & 0.004 & 0.007 & 0.045 & 0.038 \\
\hline & $n$ & 181 & 181 & 137 & 134 & 141 & 136 & 132 & 132 \\
\hline
\end{tabular}

\footnotetext{
* Period 1, March and April 1995; period 2, June and July 1995; period 3, October 1995; period 4, January and February 1996; periods 2 and 3, rainy season.

† Spearman correlation between nutritional density (expressed as $\mathrm{mg}$ or $\mu \mathrm{g}$ vitamin intake/5 MJ) and biological status (standardised values).

$\ddagger$ Spearman correlation between absolute daily dietary intake and biological status adjusted by age, years of education, BMI, number of cigarettes smoked per d, number of vitamin tablets per week, energy and alcohol intake (standardised values).
} 
The measure of static and functional status indices gives more precise information on the prevalence of deficiency in vitamin B complex status. However, the results largely depend on the method used for their determination, and there is currently no clearly accepted cut-off values for vitamin B complex deficiencies (Van den Berg et al. 1993; Tucker et al. 2000). The cut-off values used are based on the proposals of a European group of experts (Van den Berg et al. 1993) and the values obtained in well-nourished populations using the same methods. Nevertheless, compared with studies conducted in men from developed countries and the laboratories' reference values, the Cuban population studied was deficient in thiamin, riboflavin, folate and vitamin $\mathrm{B}_{12}$, whereas pyridoxal status was similar (Van den Berg et al. 1993; Costa de Carvalho et al. 1996; Benton et al. 1997; Brussaard et al. 1997a,b; Ford \& Bowman, 1999; Tucker et al 2000). Compared with values observed in Cuba at the beginning of the neuropathy epidemic in 1992, serum folate and vitamin $\mathrm{B}_{12}$ concentrations were lower (Pérez-Cristià \& Fleites-Mestre, 1994), and thiamin status was more deficient (Macias-Matos et al. 1996). Unfortunately, riboflavin and vitamin $B_{6}$ biological status was not measured in 1992. In addition, the pyridoxal status of the Cuban men studied remained within the reference range despite a low vitamin $\mathrm{B}_{6}$ daily dietary intake. These results may reflect the difficulty of measuring accurately the intake by using diet records and the accurate evaluation of recommended dietary intake; they could also be explained by the low protein intake. Indeed, low protein intake has been reported to increase plasma vitamin $B_{6}$ concentrations (Hansen et al. 1996).

In contrast, the high prevalence of thiamin, riboflavin, folate and vitamin $\mathrm{B}_{12}$ deficiencies previously observed in developing countries results from inadequate intake, low income, type of food consumed, smoking habits and possibly in vivo photolysis (Branda \& Eaton, 1978; Tucker \& Hedges, 1993; Bates et al. 1994; Sainte-Foie et al. 1997; Bovet et al. 1998). The typical Cuban diet is rich in rice and beans. The high daily dietary carbohydrate intake (approximately $60 \%$ daily dietary energy intake) as well as the high consumption of polished rice (approximately $18 \%$ total food intake) observed in the present study could contribute to the marginal thiamin status, as previously observed in other tropical countries (Bovet et al. 1998). In addition, the relatively low consumption of food rich in riboflavin and vitamin $\mathrm{B}_{12}$ (i.e. meat and dairy products) in Cuba could partially account for the deficient riboflavin and vitamin $\mathrm{B}_{12}$ status (Bates et al. 1994; Costa de Carvalho et al. 1996). The deficient folate status could be attributed to the low consumption of green vegetables, liver and yeast compared with previous studies (Guilland et al. 1986; Brants et al. 1997; Alberti-Fidanza et al. 1998; Ford \& Bowman, 1999), but also to the method used. Indeed, using the cut-off value proposed by the manufacturer ( $3.4 \mathrm{nmol} / \mathrm{l})$, the percentage of deficient volunteers varied from $21 \%$ in October 1995 to $50 \%$ in June-July 1995. In contrast, in the present study alcohol consumption was probably not an important contributing factor to vitamin B complex status. Alcoholism is recognised as having a negative effect on vitamin B complex status (Costa de Carvalho et al. 1996; Benton et al. 1997; Brussaard et al. 1997a,b; Alberti-Fidanza et al. 1998; Bovet et al. 1998; Ford \& Bowman, 1999), but vitamin B complex status is generally not modified in moderate drinkers such as those in the Cuban population studied (Benton et al. 1997; Brussaard et al. 1997b). Indeed, $<6 \%$ of the volunteers presented with $\gamma$-glutamyl transferase activity $>75 \mathrm{IU} / 1$ (results not shown) and the average alcohol consumption was $9.5 \mathrm{~g} / \mathrm{d}$. Tobacco use could also contribute to riboflavin deficiency (Benton et al. 1997), but its effect on thiamin, folate and vitamin $\mathrm{B}_{12}$ deficiencies remains unclear (Macias-Matos et al. 1996; Benton et al. 1997; Brussaard et al. 1997b; Bovet et al. 1998; Ford \& Bowman, 1999). Moreover, and as reported elsewhere (Barnouin et al. 2000), a more deficient riboflavin status was observed in Cuban smokers than in Cuban non-smokers, whereas thiamin, folate and vitamin $B_{12}$ status were similar in smokers and non-smokers. The low serum folate and vitamin $B_{12}$ concentrations suggest the need for the determination of more sensitive and specific markers of vitamin $B_{12}$ deficiency (i.e. serum methylmalonic acid; Stabler et al. 1996) and folate deficiency (i.e. erythrocyte folate; Van den Berg et al. 1993). Nevertheless, these very low serum folate and vitamin $\mathrm{B}_{12}$ concentrations could contribute to the rather high serum homocysteine concentrations (mean 18.4 (range 8.6-77.9 $\mu \mathrm{mol} / \mathrm{l}$ ) observed in the La Lisa volunteers in April 2000 (V Ducros, P FleitesMestre, R Perez-Christià and $\mathrm{J}$ Barnouin, unpublished results), compared with the reference values of the laboratory (Ducros et al. 1999). Finally, the deficient vitamin B complex status in the Cuban population studied suggests that clinical deficiencies were likely to develop if conditions worsened.

To our knowledge, few studies have reported seasonal variations in vitamin B complex intake and status, especially in tropical countries. Moreover, the seasonal variations observed in Cuba were difficult to compare with those of previous studies, which were performed in countries where income, seasonal changes in diet and sunlight exposure (Branda \& Eaton, 1978) are completely different. In addition, biochemical determinations must be performed a short while after sampling because of changes during storage. However, precautions were taken to limit between-run differences. Variation in thiamin intake was different from that observed in France (Guilland et al. 1986). In French men thiamin intake has been reported to be lower in spring and summer than in autumn and winter. With regard to EGR-AC variation, our results did not completely match the riboflavin status improvement from July to October, and the riboflavin status decline from December to March reported in Gambian women (Bates et al. 1994). Riboflavin intake remained similar throughout the year in Havana, as previously observed in French men (Guilland et al. 1986), but in contrast with the paradoxical decrease observed in Gambian women during the rainy season (Bates et al. 1994). The similar consumption of dairy products over the year could partly contribute to the similar daily dietary intake of riboflavin throughout the year. As vitamin $\mathrm{B}_{6}$ is widely distributed in food (Benton et al. 1997), variation in vitamin $B_{6}$ intake and status throughout the year was not expected. Moreover, in French men vitamin $\mathrm{B}_{6}$ intake has been reported to remain similar 
throughout the year (Guilland et al. 1986). For folate, the daily dietary intake of Havanan men and serum concentrations were the lowest in June and July, which contrasts with the improvement in folate intake and erythrocyte folate concentration in June and July observed in Gambian women (Bates et al. 1994), and with the increase in serum folate concentration during the summer observed in elderly British men (Clarke et al. 1998). However, in the present study, fruit and vegetable consumption and folate intake variation followed those described in previous studies (Costa de Carvalho et al. 1996; Bell et al. 1998; Ford \& Bowman, 1999). For vitamin $B_{12}$, the improvement in serum concentrations observed between June 1995 and October 1995 in the Havanan population studied contrasts with the stability observed throughout the year in elderly British men (Clarke et al. 1998). Further work is needed to better evaluate seasonal variation using a higher frequency of repeated measures for each volunteer.

Thiamin intake and status were not correlated, in agreement with previous studies carried out in developed and developing countries (Costa de Carvalho et al. 1996; Alberti-Fidanza et al. 1998; Bovet et al. 1998). The significance of Spearman correlations between riboflavin, vitamin $\mathrm{B}_{6}$ and folate intake and status depended on period, intake expression (absolute intake or nutritional density) and adjustment. Significant correlations $P<0.05$ between riboflavin and vitamin $\mathrm{B}_{6}$ intake and biological status have been reported by Hercberg et al. (1994), but not by other researchers (Costa de Carvalho et al. 1996; Brussaard et al. 1997a; Alberti-Fidanza et al. 1998). Contrary to previous observations (Costa de Carvalho et al. 1996; Brussaard et al. 1997b), serum folate concentrations were not strongly influenced by recent folate dietary intake. However, the folate and vitamin $\mathrm{B}_{6}$ nutritional density related more to the corresponding biological status, suggesting that the type of consumed food is an important confounding factor. Moreover, several determined and undetermined factors could influence the relationship between intake and corresponding biological status. First, the estimation of daily dietary intake using food composition tables does not adequately take into account the modifications of vitamin content during cooking (Costa de Carvalho et al. 1996; AlbertiFidanza et al. 1998; Bovet et al. 1998) and could contribute to the lack of correlation between thiamin intake and status. Second, vitamin B complex bioavailability depends on the type of food consumed (Costa de Carvalho et al. 1996; Brants et al. 1997; Brussaard et al. 1997a; Alberti-Fidanza et al. 1998) and could explain the period effect on the significance of correlation. Third, changes in intake are counterbalanced by modifications in metabolism (i.e. absorption, tissue mobilisation and excretion) and could also contribute to the period effect on the significance of the correlation. Finally, vitamin B complex status can be affected by nutritive and non-nutritive factors (Van den Berg et al. 1993), as suggested by modifications in the correlation models. Adjustment for variables known to affect vitamin B complex status, including age, years of education, BMI, smoking habits, vitamin supplement use, energy and alcohol intake, modified the correlation between folate intake and status in periods 1,3 and 4 , and between vitamin $B_{6}$ intake and status in periods 1 and
2. These results suggest that the folate and vitamin $B_{6}$ dietblood associations are confounded by one or more of these variables and that they should be adjusted in studies that assess these associations (Tomassone et al. 1993).

In conclusion, our results clearly demonstrate that the apparently healthy Cuban men selected in the present study represent a group potentially vulnerable to developing clinical vitamin B complex deficiencies. Under these conditions, the subject's health would deteriorate, particularly in the presence of increased requirements relating to illness, intensive training or food shortage resulting from hurricane or plagues. Thus, the development of a policy to promote the production and supply of food rich in vitamin B complex must be encouraged, and multivitamin supplementation programmes must be maintained in the meantime. Further work is nevertheless needed to better investigate the dysfunction generated by folate and vitamin $\mathrm{B}_{12}$ deficiencies and to better identify the relationship between vitamin B complex intake, seasonal food consumption and status.

\section{Acknowledgements}

The authors are particularly indebted to Nestec-Nestlé, Merck-Biotrol Diagnostics and the Trace Element Institute for UNESCO for their financial support, and to Pharmaciens sans Frontières for logistical help. The authors also thank the Cuban volunteers who participated in the study, as well as the technicians, nurses, physicians and researchers involved.

\section{References}

Alberti-Fidanza A, Burini G, Genipi L, Maurizi-Coli A \& Fidanza F (1998) Vitamin intake and status in a group of subjects from the Gubbio area (Italy). International Journal for Vitamin and Nutrition Research 68, 249-254.

Anon (1994) Protection des personnes qui se prêtent à des recherches biomédicales (Guidelines on the practice of ethics committees involved in medical research involving human subjects). Journal Officiel de la République Française 1074710749.

Arnaud J, Fleites P, Chassagne M, Verdura T, Barnouin J, Richard MJ, Charcornac JP, Garcia Garcia I, Perez-Cristià R \& Favier A (2001) Seasonal variations of antioxidant imbalance in Cuban healthy men. European Journal of Clinical Nutrition 55, 29-38.

Barnouin J \& Pérez-Cristià R (1998) Risques Toxico-nutritionnels Neuropathie Épidémique et Sécurité Alimentaire à Cuba (Toxic-nutritional Neuropathy Epidemic Risks and Food Safety in $\mathrm{Cu}$ ba). Clermont-Ferrand, France: INRA.

Barnouin J, Pérez-Cristià R, Chassagne M, Verdura Barrios T, Arnaud J, Fleites Mestre P \& Favier A (2000) Vitamin and nutritional status in Cuban smokers and nonsmokers in the context of an emerging epidemic neuropathy. International Journal for Vitamin and Nutrition Research 70, 126-138.

Bates CJ, Prentice AM \& Paul AA (1994) Seasonal variations in vitamins A, C, riboflavin and folate intake and status of pregnant and lactating women in a rural Gambian community: some possible implications. European Journal of Clinical Nutrition 48, 660-668.

Bayoumi RA \& Rosalki SB (1976) Evaluation of methods of coenzyme activation of erythrocyte enzymes for detection of 
deficiency of vitamins $\mathrm{B}_{1} \mathrm{~B}_{2}$ and $\mathrm{B}_{6}$. Clinical Chemistry 22, 327-335.

Bell M, Wilbur L \& Smith C (1998) Nutritional status of persons using a local emergency food system program in middle America. Journal of the American Dietetic Association 98, 1031-1033.

Benton D, Haller J \& Fordy J (1997) The vitamin status of young British adults. International Journal for Vitamin and Nutrition Research 67, 34-40.

Bovet P, Larue D, Fayol V \& Paccaud F (1998) Blood thiamin status and determinants in the population of Seychelles (Indian Ocean). Journal of Epidemiology and Community Health 52, 237-242.

Bowman BA, Bern C \& Philen RM (1996) Nothing's simple about malnutrition: complexities raised by epidemic neuropathy in Cuba. American Journal of Clinical Nutrition 64, 383-384.

Branda RF \& Eaton JW (1978) Skin color and nutrient photolysis: an evolutionary hypothesis. Science 201, 625-626.

Brants HAM, Brussaard JH, Bouman M \& Löwik MRH (1997) Dietary intake among adults with special reference to vitamin $\mathrm{B}_{6}$. European Journal of Clinical Nutrition 51, S25-S31.

Brussaard JH, Löwik MRH, Van den Berg H, Brants HAM \& Bemelmans W (1997a) Dietary and other determinants of vitamin $\mathrm{B}_{6}$ parameters. European Journal of Clinical Nutrition 51, S39-S45.

Brussaard JH, Löwik MRH, Van den Berg H, Brants HAM \& Goldbohm RA (1997b) Folate intake and status among adults in The Netherlands. European Journal of Clinical Nutrition 51, S46-S50.

Clarke R, Woodhouse P, Ulvik A, Frost C, Sherliker P, Refsum H, Ueland PM \& Khaw KT (1998) Variability and determinants of total homocysteine concentrations in plasma in an elderly population. Clinical Chemistry 44, 102-107.

Costa de Carvalho MJ, Guilland JC, Moreau D, Boggio V \& Fuchs F (1996) Vitamin status of healthy subjects in Burgundy (France). Annals of Nutrition and Metabolism 40, 24-51.

Dolin PJ, Mohamed AA \& Plant GT (1998) Epidemic of bilateral optic neuropathy in Dar es Salaam, Tanzania. New England Journal of Medicine 338, 1547-1548.

Ducros V, Schmitt D, Pernod G, Faure H, Polack B \& Favier A (1999) Gas chromatographic-mass spectrometric determination of total homocysteine in human plasma by stable isotope dilution: method and clinical application. Journal of Chromatography B 729, 333-339.

Ford ES \& Bowman BA (1999) Serum and red blood cell folate concentrations, race, and education: findings from the third National Health and Nutrition Examination Survey. American Journal of Clinical Nutrition 69, 476-481.

Guilland JC, Boggio V, Moreau D \& Klepping J (1986) Evaluation de l'apport alimentaire vitaminique en Bourgogne (France) (A survey of the daily vitamin intake in Burgundy (France)). Annals of Nutrition and Metabolism 30, 21-46.

Hansen CM, Leklem JE \& Miller LT (1996) Vitamin B-6 status of women with a constant intake of vitamin B-6 changes with three levels of dietary protein. Journal of Nutrition 126, 18911901.

Hercberg S, Preziosi P, Galan P, Devanlay M, Keller H, Bourgeois C, Potier de Courcy G \& Cherouvrier F (1994) Vitamin status of a healthy French population: dietary intake and biochemical markers. International Journal for Vitamin and Nutrition Research 64, 220-236.

Lei X, David D, Kuan L, Lee J \& Oh S (1998) The conditional binomial test revisited for clinical trials. Journal of Biopharmaceutical Statistics 8, 533-543.

Littell RC, Henry PR \& Ammerman CB (1998) Statistical analysis of repeated measures data using SAS procedures. Journal of Animal Science 76, 1216-1231.

Macias-Matos C, Rodriguez-Ojea A, Chi N, Jimenez S, Zulueta D \& Bates CJ (1996) Biochemical evidence of thiamine depletion during the Cuban neuropathy epidemic, 1992-1993. American Journal of Clinical Nutrition 64, 347-353.

National Research Council (1989) Recommended Dietary Allowances, 10th ed. Washington, DC: National Academy Press.

Nichoalds GE, Lawrence JD \& Sauberlich HE (1974) Assessment of status of riboflavin nutriture by assay of erythrocyte glutathione reductase activity. Clinical Chemistry 20, 624-628.

Pérez-Cristià R \& Fleites-Mestre P (1994) Toxic-nutritional factors in the epidemic neuropathy. In International Workshop on the Epidemic Neuropathy occurring in Cuba, pp. 1-31 [Toxic-Nutritional Subgroup, editors]. Havana: Ministerio de Salud Publica - Organizacion Panamericana de la Salud (OPS/ OMS).

Rodriguez A, Gay J, Prieto Y, Suarez A, Martin I \& Siberio I (1992) Nutrisis Version 4.02 (Subsistema de VAD: Sistema para la Vigilancia Automatizada de Dietas) Automatised system for the follow up of dietary intakes and food consumption. Havana: Institute of Nutrition and Food Hygiene, Ministry of Public Health.

Roman GC (1994) An epidemic in Cuba of optic neuropathy, sensorineural deafness, peripheral sensory neuropathy and dorsolateral myeloneuropathy. Journal of the Neurological Sciences 127, 11-28.

Sainte-Foie S, Bourhis V, Joly F \& Petit-Bon J (1997) Neuromyélopathies dans la population de Noirs marrons de Saint Laurent du Maroni en Guyane francaise (Myelo neuropathies among 'Noirs-Marons' individuals of Saint Laurent du Maroni in French Guyana). Bulletin de la Société de Pathologie Exotique 90, 113-116.

Stabler SP, Lindenbaum J \& Allen RH (1996) The use of homocysteine and other metabolites in the specific diagnosis of vitamin $\mathrm{B}_{12}$ deficiency. Journal of Nutrition 126, 1266S$1272 \mathrm{~S}$.

Tomassone R, Dervin C \& Masson JP (1993) Biométrie, Modélisation de Phénomènes Biologiques (Biometrics, Modelling of Biological Phenomena). part 5, Dépendance et Corrélation (Dependence and Correlation), pp. 98-109. Paris: Masson.

Tucker K \& Hedges TR (1993) Food shortages and an epidemic of optic and peripheral neuropathy in Cuba. Nutrition Reviews 51, 349-357.

Tucker KL, Rich S, Rosenberg I, Jacques P, Dallal G, Wilson PWF \& Selhub J (2000) Plasma vitamin B-12 concentrations relate to intake source in the Framingham offspring study. American Journal of Clinical Nutrition 71, 514-522.

Van den Berg H, Heseker H, Lamand M, Sandström B \& Thurnham D (1993) Flair Concerted Action no. 10 status paper. International Journal for Vitamin and Nutrition Research 63, 247-316. 